\title{
2011s-03 \\ Technological Choices, Productivity and Labour Market Participation
}

\author{
Samir Amine, Pedro Lages Dos Santos
}

Série Scientifique
Scientific Series

\section{Montréal \\ Janvier 2011}

(C) 2011 Samir Amine, Pedro Lages Dos Santos. Tous droits réservés. All rights reserved. Reproduction partielle permise avec citation du document source, incluant la notice $($.

Short sections may be quoted without explicit permission, if full credit, including () notice, is given to the source.
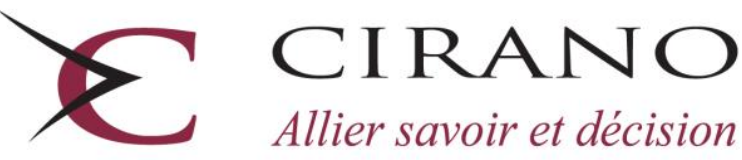

Allier savoir et décision

Centre interuniversitaire de recherche en analyse des organisations 


\section{CIRANO}

Le CIRANO est un organisme sans but lucratif constitué en vertu de la Loi des compagnies du Québec. Le financement de son infrastructure et de ses activités de recherche provient des cotisations de ses organisations-membres, d'une subvention d'infrastructure du Ministère du Développement économique et régional et de la Recherche, de même que des subventions et mandats obtenus par ses équipes de recherche.

CIRANO is a private non-profit organization incorporated under the Québec Companies Act. Its infrastructure and research activities are funded through fees paid by member organizations, an infrastructure grant from the Ministère du Développement économique et régional et de la Recherche, and grants and research mandates obtained by its research teams.

\section{Les partenaires du CIRANO}

Partenaire majeur

Ministère du Développement économique, de l'Innovation et de l'Exportation

\section{Partenaires corporatifs}

Banque de développement du Canada

Banque du Canada

Banque Laurentienne du Canada

Banque Nationale du Canada

Banque Royale du Canada

Banque Scotia

Bell Canada

BMO Groupe financier

Caisse de dépôt et placement du Québec

Fédération des caisses Desjardins du Québec

Financière Sun Life, Québec

Gaz Métro

Hydro-Québec

Industrie Canada

Investissements PSP

Ministère des Finances du Québec

Power Corporation du Canada

Raymond Chabot Grant Thornton

Rio Tinto

State Street Global Advisors

Transat A.T.

Ville de Montréal

\section{Partenaires universitaires}

École Polytechnique de Montréal

HEC Montréal

McGill University

Université Concordia

Université de Montréal

Université de Sherbrooke

Université du Québec

Université du Québec à Montréal

Université Laval

Le CIRANO collabore avec de nombreux centres et chaires de recherche universitaires dont on peut consulter la liste sur son site web.

Les cahiers de la série scientifique (CS) visent à rendre accessibles des résultats de recherche effectuée au CIRANO afin de susciter échanges et commentaires. Ces cahiers sont écrits dans le style des publications scientifiques. Les idées et les opinions émises sont sous l'unique responsabilité des auteurs et ne représentent pas nécessairement les positions du CIRANO ou de ses partenaires.

This paper presents research carried out at CIRANO and aims at encouraging discussion and comment. The observations and viewpoints expressed are the sole responsibility of the authors. They do not necessarily represent positions of CIRANO or its partners. 


\title{
Technological Choices, Productivity and Labour Market Participation
}

\author{
Samir Amine*, Pedro Lages Dos Santos ${ }^{*}$
}

\begin{abstract}
Résumé / Abstract
Nous étudions, dans cet article, le rôle des allocations chômage dans la détermination de la nature des emplois offerts. Nous montrons qu'un système d'indemnisation du chômage généreux, en provoquant une accentuation de la sélectivité des agents, affecte les caractéristiques des emplois créés qui deviennent plus complexes et aboutit ainsi à améliorer la productivité du travail. Or, malgré cette amélioration de la qualité des appariements, la participation au marché du travail diminue.
\end{abstract}

Mots clés : Appariement, complexité, allocations chômage, productivité et participation.

This article aims at understanding the interactions between public policies, such as unemployment benefit systems, and firms' technological choices. For this purpose, we use a matching model in which workers are vertically differentiated and where the nature of jobs is endogenous. We show that an improvement in unemployment benefits leads to an increase in productivity by making agents more selective and jobs more complex. However, the impact on labour market participation is negative.

Keywords: Job Complexity, unemployment benefits, productivity, participation.

\footnotetext{
*Université du Québec en Outaouais, Pavillon Alexandre-Taché, 283 boulevard Alexandre Taché, bureau C3805, Case postale 1250, Gatineau, Québec, Canada, J8X 3X7, samir.amine@uqo.ca

† Université du Havre, Faculté des Affaires internationales, 25 rue Philippe Lebon, BP. 420, 76057 Le Havre Cedex, France, pedro.lages@univ-lehavre.fr
} 


\section{Introduction}

Growth in pay inequalities, at the expense of less qualified workers, is certainly one of the major labour market trends in developed economies (Barrell and al. 1995; Machin and Reenen 1998; Manacorda and Petrongolo 1999). In the theoretical and empirical literature, many authors (Acemoglu 2002 and 2003; Aghion and Howitt 2002) agree that the currently deteriorating situation for unskilled workers is largely explained by biased technological progress.

Against this background of biased technological progress, the impact of rigidity or flexibility has generated considerable reflection (Agell 1999; Siebert 1997). According to one wide spread idea, labour market rigidity is what causes unemployment. In other words, a labour market constrained by strict public regulations is believed to be unfavorable to employment. Such regulations are considered by some to exert a negative effect on employment, by increasing the cost of work and reducing incentives to work (Boone and Van Ours 2000; Shavell and Weiss 1979). In contrast, a flexible labour market is argued to encourage job creation, but also to provide fertile ground for increasing inequalities (Diamond 1981; Galor and Maov 2000; Saint-Paul 1995).

In order to understand institutions' effects on the labour market situation, we need to analyze the causes and nature of this biased technological progress, or "technological bias". In this article, we introduce a new vision of interactions between technological choices and public policies such as unemployment benefit policies. In this model, job complexity is considered to result from firms' choices. Opting for complexity, which endogenizes the technological bias, is a rational response to the state of the labour market. Unemployment, in this paper, becomes the cause, not the effect of job complexity.

We use a dynamic matching model (Pissarides 2000) in which heterogeneous workers are vertically differentiated according to qualification level (Strand 2000 and 2002). Firms, in contrast, are assumed to be identical and to offer a single homogeneous job. The meeting process between the two agents is formalized by a constant returns matching function.

Workers' productivity depends both on their qualification level and the degree of job complexity. In accordance with intuition, we presume that only qualified workers take advantage of job complexity. In other words, our model reflects the complementarity between complexity and qualification level. In this context, only workers with sufficient ability (i.e. qualification level) will participate in the labour market. An ability threshold is thus defined. All workers whose ability is below this threshold are considered unemployable and excluded from the labour market. We will show that this threshold plays a key role in the determination of job complexity.

According to the literature, unemployment benefits reduce the incentives to seek a job and increase the reservation wage (Boone and Van Ours 2004; Machin 
and Manning 1999). These effects combine to increase the unemployment period (Hopenhayn and Nicolini 1997). Nevertheless, some theoretical research shows that unemployment benefits can have a positive impact on job creation (Cahuc and Lehmann 2000; Fredriksson and Holmlund 2001).

Considering that job complexity results from firms' choices, we show that a public policy such as an unemployment benefit system can be favorable to skilled workers and appears to affect technological choices. By making job-seekers more selective, an increase in unemployment benefit appears to incite firms to adapt the characteristics of their jobs to skilled workers, thus creating more complex jobs. In spite of the resulting improvement in productivity, this public policy has a negative impact on labour market participation.

The rest of this paper is organized as follows. The Model and the market structure are presented in Section 2. The solution to the model and the definition of its equilibrium are discussed in Section 3. Section 4 defines and studies the model's comparative static properties, and the paper concludes in Section 5 .

\section{The Model}

Consider an economy populated by a large exogenous number of workers and a large endogenous number of firms. Each firm offers a single job. All firms and workers are risk-neutral and have the same rate of time preference, denoted by $r$.

Workers are vertically differentiated by their qualification level and have an infinite horizon (Strand, 2002). Each worker's ability $z$ is a constant, implying that productivity differences are purely general. In the worker population, $z$ is distributed according to a continuous distribution, $G(z)$, with support $z \in$ $\left[z_{\min }, Z\right]$. The density of $G(z)$ is denoted by $g(z)$.

In contrast to workers, firms in this economy are identical. The exogenous destruction rate is $s$. Nevertheless, we assume firms have free entry, in order to maintain a fixed number of firms at the stationary state.

\subsection{Productivity and Participation}

Each firm- $i$ in this economy requires its future worker to have a minimal ability (i.e. qualification level), called $\hat{z}_{i}$. All workers with an ability below $\hat{z}_{i}$ are excluded from the labour market and considered not economically active.

In addition, a firm that enters the labour market with a vacant job must define the job's degree of complexity in order to maximize its value. This endogenous determination of production technology based on labour market conditions is a key point of our analysis. 
We assume that the productivity of a job- $i$ depends both on the degree of the job's complexity and the ability (i.e. qualification level) of the worker who is occupying it. Formally, the productivity of a job- $i$, noted $y_{i}\left(a_{i}, z\right)$, is considered to be an increasing linear function of ability $z$ :

$$
y_{i}\left(a_{i}, z\right)=A\left(a_{i}\right)+a_{i} z
$$

In this equation, the endogenous variable $a_{i}\left(a_{i} \geq 0\right)$ measures the degree of complexity of the job offered by firm- $i$. Intuition suggests that an increase in complexity should raise skilled workers' productivity but reduce unskilled workers' productivity. It is easy to see that, formally, this hypothesis requires $A\left(a_{i}\right)$ to be a decreasing function. In order to verify this hypothesis, we consider the specific ability level, denoted $\tilde{z}_{i}$, such that an increase in $a_{i}$ leaves productivity $y_{i}\left(a_{i}, \tilde{z}_{i}\right)$ unchanged:

$$
\frac{\partial y_{i}\left(a_{i}, \tilde{z}_{i}\right)}{\partial a_{i}}=0 \quad \Longleftrightarrow \quad \tilde{z}_{i}=-A^{\prime}\left(a_{i}\right)>0
$$

By substitution, we have

$$
\frac{\partial y_{i}\left(a_{i}, z\right)}{\partial a_{i}}=z_{i}-\tilde{z}_{i}
$$

We observe that an increase in $a_{i}$ leads to a rise in productivity for workers whose ability is above $\tilde{z_{i}}$ and a decline in productivity for workers whose ability is below $\tilde{z_{i}}$. It seems logical to consider that the proportion of workers whose ability allows for an increase in the degree of complexity decreases (increase of $\left.\tilde{z}_{i}\right)$ as job complexity increases. In other words, a continuing rise in complexity has a negative effect on the proportion of employable workers. This can be expressed through the following concave $A\left(a_{i}\right)$ function:

$$
\frac{d \tilde{z}_{i}}{d a_{i}}=-A^{\prime \prime}\left(a_{i}\right)>0
$$

As noted above, we are only interested in the effects of technological bias (Figure 1). In this case, increasing the degree of complexity implies a rise in the productivity of skilled workers on the one hand, and a decrease in the productivity of unskilled workers on the other. Formally, this is equivalent to admitting that the threshold ability $\hat{z_{i}}$ is lower than $\tilde{z_{i}}$. We conclude that:

$$
\frac{\partial y_{i}\left(a_{i}, \hat{z}_{i}\right)}{\partial a_{i}}<0 \quad \Longleftrightarrow \quad \hat{z}_{i}+A^{\prime}\left(a_{i}\right)<0 \quad \Longleftrightarrow \quad \hat{z}_{i}<\tilde{z}_{i}
$$

In fact, each firm- $i$ decides on the degree of complexity based on the fact that only qualified workers can take advantage of an increase in complexity $A^{\prime}\left(a_{i}\right)<0$. This complementarity relation between qualification and technology has been discussed in several papers, both theoretical (Autor and al. 1998; 
Funk and Vogel 2004) and empirical (Bound and Johnson 1992; Berman and al. 1994). In a general equilibrium framework, Acemoglu (1998) also shows that only skilled workers are able to implement new technologies in firms.

In summary, setting a minimum ability (i.e. qualification level) allows the firm to determine the characteristics of its future worker (low or high $z$ ) and make a technological choice appropriate to the ability of workers who are able to occupy its vacant job.

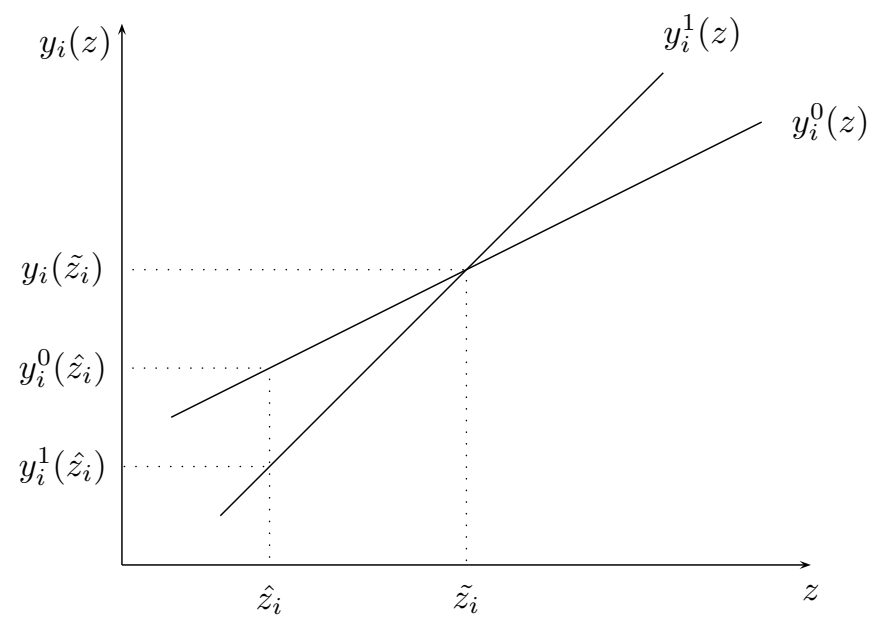

Figure 1: Job Complexity and Productivity

\subsection{Hiring Process}

There are frictions in the labour market that prevent instantaneous matching of employable unemployed workers and vacant jobs. Let, $\theta$, represent the labour market tightness (i.e. the ratio of vacant jobs, $V$, to employable unemployed workers $U$ ). Meetings between firms with a vacant job and employable unemployed workers are summarized by a constant-returns matching function (Pissarides 2000).

Formally, the matching function, noted $\pi(V, U)$, is a degree 1 homogenous function and an increasing function in $V$ and $U$. Thus, the probability that a firm will meet an employable worker is:

$$
q=\frac{\pi(V, U)}{V}=\pi\left(1, \frac{1}{\theta}\right)=q(\theta)
$$


It is clear that this probability is decreasing in $\theta$. Owing to the congestion effect, a rise in the number of vacant jobs has a negative impact on the probability of filling a job. Concerning workers, the hiring probability, denoted $p$, is written as follows :

$$
p=\theta q(\theta)=p(\theta)
$$

Contrary to $q(\theta)$, the probability that an employable worker will find a job is an increasing function of $\theta$. In other words, a rise in the number of vacant jobs provides workers with more opportunities to find a job.

\subsection{Utilities and Profits}

The following analysis is restricted to a symmetric stationary state, where all firms but $i$ have set the same degree of complexity $a$ and the same ability threshold $\hat{z}$. At this stage, the pair $(a, \hat{z})$ is seen as exogenous. In the next sections, we will show that the choice made by firm- $i,\left(a_{i}, \hat{z}_{i}\right)$, derives from the optimization of the vacant job value.

Let us consider the expected lifetime utility of an employable worker with ability $z$. At the stationary state, if this worker holds job- $i$, his/her lifetime utility $W_{i}(z)$ depends on the wage $w_{i}(z)$ and the destruction rate $s$.

We assume that unemployed workers' income is composed of unemployment benefits $b$ and productivity of household production $\mu$. Their expected lifetime utility $W_{u}(z)$, depends on the probability $p(\theta)$ of finding a job. As a result, at the stationary state, utilities $W_{i}(z)$ and $W_{u}(z)$ satisfy :

$$
\begin{gathered}
r W_{i}(z)=w_{i}(z)-s\left(W_{i}(z)-W_{u}(z)\right) \\
r W_{u}(z)=b+\mu+p(\theta)\left(W(z)-W_{u}(z)\right)
\end{gathered}
$$

where $W(z)$ is the lifetime utility of workers with ability $z$ when holding a job other than $i$. As there are a large number of firms, the probability of unemployed workers being hired for job- $i$ is almost zero.

We consider that the firms' jobs are either vacant or filled. The value of job- $i$ filled with a worker with ability $z, J_{i}(z)$, depends on the net instantaneous income $\left(y_{i}\left(a_{i}, z\right)-w_{i}(z)\right)$ and the future profits, taking into consideration that the firm can die at any time with probability $s$. It satisfies:

$$
r J_{i}(z)=y_{i}\left(a_{i}, z\right)-w_{i}(z)-s\left(J_{i}(z)-J_{v i}(z)\right)
$$

Until its job is filled, firm- $i$ must invest $c$ to create the job and to look for a worker. Furthermore, opening a new job is more profitable if probability $q(\theta)$ is high. The value of a vacant job- $i$ depends on the conditional expected value $\bar{J}_{i}$, and is given by:

$$
\bar{J}_{i}=\frac{1}{1-G\left(\hat{z}_{i}\right)} \int_{\hat{z}_{i}}^{Z} J_{i}(z) g(z) d z
$$


Firm- $i$ is too small to attract workers of lower ability than $\hat{z}$. This means that threshold $\hat{z}_{i}$ cannot be lower than $\hat{z}$. Under this condition, the value $J_{v i}$ satisfies :

$$
r J_{v i}=-c+\frac{q(\theta)}{1-G(\hat{z})} \int_{\hat{z_{i}}}^{Z}\left(J_{i}(z)-J_{v i}\right) g(z) d z
$$

Taking into account the free-entry assumption $\left(J_{v}=0\right)$, we presume that new jobs will be created until the optimal value of a vacant job is equal to zero. In addition, the job- $i$ average productivity $\bar{y}_{i}$ and average wage $\bar{w}_{i}$ are given by:

$$
\begin{gathered}
\bar{y}_{i}=\frac{1}{1-G\left(\hat{z_{i}}\right)} \int_{\hat{z}_{i}}^{Z} y_{i}\left(a_{i}, z\right) g(z) d z \\
\bar{w}_{i}=\frac{1}{1-G\left(\hat{z}_{i}\right)} \int_{\hat{z}_{i}}^{Z} w_{i}(z) g(z) d z
\end{gathered}
$$

\subsection{Wage Bargaining and Surplus Sharing}

In accordance with traditional matching models, the surplus created by a firm/worker is divided between the two agents according to their respective bargaining strength. If $\beta(0<\beta<1)$ represents the workers' bargaining strength, the maximization program for firm- $i$ is:

$$
\max _{w_{i}(z)}\left(W_{i}(z)-W_{u}(z)\right)^{\beta}\left(J_{i}(z)-J_{v i}\right)^{(1-\beta)}
$$

The solution to this program implies that the overall surplus, $S_{i}(z)$, is divided between the two agents as follows:

$$
\begin{gathered}
W_{i}(z)-W_{u}(z)=\beta\left(W_{i}(z)-W_{u}(z)+J_{i}(z)-J_{v i}\right)=\beta S_{i}(z) \\
J_{i}(z)-J_{v i}=(1-\beta)\left(W_{i}(z)-W_{u}(z)+J_{i}(z)-J_{v i}\right)=(1-\beta) S_{i}(z)
\end{gathered}
$$

At the stationary equilibrium, the number of workers who lose their job must equal the number of unemployed workers who find a job. This equilibrium condition implies :

$$
p(\theta) U=s L=s(N-U)
$$

Thus, the equilibrium unemployment rate $u$ is a function of the hiring probability $p(\theta)$ :

$$
u=\frac{s}{s+p(\theta)}
$$

For a given level of $p(\theta)$, an increase in the destruction rate $s$ leads to a rise in the equilibrium unemployment rate. Conversely, the equilibrium unemployment rate is a decreasing function of the hiring probability $p(\theta)$ (for a given level of $s)$. 


\section{The Model Equilibrium}

Solving the model involves establishing interactions at the stationary equilibrium between labour market tightness $\theta$, degree of complexity $a$ and ability threshold $\hat{z}$. We first describe the job creation and wage-setting processes, then study and specify the optimal degree of job complexity.

\subsection{Job Creation Process}

When entering the labour market, firm- $i$ decides on the degree of complexity of the created job $\left(a_{i}\right)$ and on the ability threshold required $\left(\hat{z}_{i}\right)$. These optimal choices result from maximization of the asset value $J_{v i}$ with respect to both variables, with the constraint that $\hat{z}_{i}$ must not be lower than $\hat{z}$.

In Appendix 1, we show that $J_{v i}$ can be written as a function of the pair $\left(a_{i}, \hat{z}_{i}\right)$. We obtain the following expression:

$$
r J_{v i}=-c+\frac{q(\theta)(1-\beta)}{(r+s)(1-G(\hat{z}))} \int_{\hat{z}_{i}}^{Z}\left[y_{i}\left(a_{i}, z\right)-r\left(W_{u}(z)+J_{v i}\right)\right] g(z) d z
$$

From this relationship, we will deduce the optimal job complexity and ability threshold.

\subsection{Wage Setting}

Using equations (16) and (17), we obtain:

$$
W_{i}(z)-W_{u}(z)=\frac{\beta}{1-\beta}\left(J_{i}(z)-J_{v i}\right)
$$

Since we assume firms have free-entry and using equation (10), we deduce:

$$
W_{i}(z)-W_{u}(z)=\frac{\beta}{1-\beta} \frac{y_{i}\left(a_{i}, z\right)-w_{i}(z)}{r+s}
$$

Using equations (8) and (9), we establish a second expression for the workers' surplus :

$$
W_{i}(z)-W_{u}(z)=\frac{w_{i}(z)-b-\mu}{r+s+p(\theta)}
$$

From these two expressions of the workers' surplus $\left(W_{i}(z)-W_{u}(z)\right)$, we obtain the wage-setting equation for firm- $i$ :

$$
w_{i}(z)=y_{i}\left(a_{i}, z\right)-\frac{(1-\beta)(r+s)\left(y_{i}\left(a_{i}, z\right)-b-\mu\right)}{r+s+\beta p(\theta)}
$$


Each firm- $i$ offers a wage $w_{i}(z)$ according to the worker's productivity $y_{i}\left(a_{i}, z\right)$, and implicitly according to the job's complexity and the worker's ability. Thus, all else being equal, the greater the ability, the more the worker earns.

\subsection{Solving the Model}

\subsubsection{Optimal Job Complexity}

According to the first order optimality conditions, the derivative of $J_{v i}$ (equation $((20))$ with respect to $a_{i}$ must be equal to zero. At the symmetric equilibrium, this first order condition can be written as follows:

$$
\frac{1}{1-G(\hat{z})} \int_{\hat{z}}^{Z} z g(z) d z=-A^{\prime}(a)
$$

For a given level of $\hat{z}$ and at the symmetric equilibrium, condition (25) is reduced to the maximization of the average productivity (13) with respect to degree $a$. Taking into account the concavity of the function $A(a)$, we find that the derivative of job complexity $a$ with respect to the ability threshold $\hat{z}$ is positive:

$$
\frac{d a}{d \hat{z}}=\frac{g(\hat{z})\left(A^{\prime}(a)+\hat{z}\right)}{A^{\prime \prime}(a)(1-G(\hat{z}))}>0
$$

This gives the following result:

Proposition 1 At the symmetric equilibrium, an increase in ability threshold $(\hat{z})$ leads to a rise in job complexity (a), thus reducing the labour market participation.

This result can be easily interpreted. If firms become selective by choosing a higher minimal ability (increase in $\hat{z}$ ), two effects must be distinguished. The first is related to the jobs' characteristics. As recruitment of skilled workers becomes easier, firms create more complex jobs suitable for these more qualified workers, hence the increase in $a$. The second effect concerns labour market participation. As a result of this simultaneous rise in both selectivity and complexity, the proportion of workers considered employable decreases.

\subsubsection{Optimal Ability Threshold}

Concerning $\hat{z}_{i}$, the model gives the following conditions (see Appendix 2):

$$
\frac{\partial J_{v i}}{\partial \hat{z}_{i}} \leq 0
$$




$$
\frac{\partial J_{v i}}{\partial \hat{z}_{i}}\left(\hat{z}_{i}-\hat{z}\right)=0
$$

At the labour market symmetric state, this condition (27) is necessarily equal to zero. If we assume it is (strictly) negative, all firms are willing to hire workers whose ability is a little lower than $\hat{z}$. As a result, those workers are employable and $\hat{z}$ is not an ability threshold. We thus have :

$$
\frac{\partial J_{v i}}{\partial \hat{z}_{i}}=0
$$

At the symmetric equilibrium, this condition is equivalent to:

$$
y(a, \hat{z})=w(\hat{z})=b+\mu
$$

In conformity with intuition, equation (30) shows that in a matching model in which workers are vertically differentiated by their qualification level, marginal productivity is determined by unemployment benefits and the productivity of household production. In other words, a worker is considered employable in this economy only if his productivity (i.e. his qualification level) makes it possible to obtain a positive or nil global surplus. Intuitively, an ability threshold $\hat{z}$ is considered optimal if it cancels out the global surplus $(S(\hat{z})=0)$. In this case, the labour market participation rate, noted $\tau$, satisfies:

$$
\tau=1-G(\hat{z})
$$

In addition, the second order condition can be written as follows (see Appendix 3):

$$
-\frac{A^{\prime \prime}(a) g(\hat{z})}{1-G(\hat{z})}\left[a-\frac{a \beta p(\theta)}{(r+s+\beta p(\theta))}\right]-\left[\frac{g(\hat{z})}{1-G(\hat{z})}\right]^{2}\left(A^{\prime}(a)+\hat{z}\right)^{2} \geq 0
$$

\subsubsection{Optimal Labour Market Tightness}

In order to determine the labour market tightness $\theta$, we consider the wagesetting as the whole within $[\hat{z}, Z]$. The integration of expression (24) on this interval leads to the so-called wage-setting equation :

$$
\bar{w}=\bar{y}-\frac{(1-\beta)(r+s)(\bar{y}-b-\mu)}{r+s+\beta p(\theta)}
$$

Since we assume firms have free-entry, using the equations (10) and (12), we can establish a second expression of the average wage:

$$
\bar{w}=\bar{y}-\frac{(r+s) c}{q(\theta)}
$$


Substituting equation (33) in (34), we define another relationship between endogenous variables of the model:

$$
-c+\frac{q(\theta)(1-\beta)(\bar{y}-b-\mu)}{r+s+\beta p(\theta)}=0
$$

Thus, we define the reduced form of the basic search-matching model (Pissarides 2000) which determines ability threshold $\hat{z}$ as an implicit function of labour market tightness $\theta$ and job complexity $a$.

\subsubsection{Equilibrium}

To summarize, the labour market equilibrium is defined as follows:

$$
\left\{\begin{array}{l}
\frac{1}{1-G(\hat{z})} \int_{\hat{z}}^{Z} z g(z) d z=-A^{\prime}(a) \\
y(a, \hat{z})=w(\hat{z})=b+\mu \\
-c+\frac{q(\theta)(1-\beta)(\bar{y}-b-\mu)}{r+s+\beta p(\theta)}=0
\end{array}\right.
$$

Definition 1 The labour market equilibrium is a set of variables $\left(a^{*} ; \hat{z}^{*} ; \theta^{*}\right)$ which jointly satisfy equations (25), (30) and (35).

Notice that the model is recursive. Variables $a$ and $\hat{z}$ are obtained by combining equations (25) and (30). Then, $\theta$ is derived from equation (35).

At the equilibrium, each worker with job- $i$ will receive a wage which depends partly on his skill or ability level, $z$, and partly on the complexity of the job, $a^{*}$. Considering that firms are identical, they will require the same ability threshold, $\hat{z}$. However, they will pay different wages to workers according to the ability of each one. Consequently, the difference between the wage of a worker whose ability is greater than $\hat{z}$ and the minimum wage $w\left(\hat{z}^{*}\right)$ is positive (or, obviously, nil if $z=\hat{z}$ ) and satisfies:

$$
w(z)^{*}-w\left(\hat{z}^{*}\right)=\left[y_{i}\left(a^{*}, z\right)-\frac{(1-\beta)(r+s)\left(y\left(a^{*}, z\right)-b-\mu\right)}{r+s+\beta p\left(\theta^{*}\right)}\right]-(b+\mu)
$$

This gives :

$$
w(z)^{*}-w\left(\hat{z}^{*}\right)=\frac{\beta\left(r+s+p\left(\theta^{*}\right)\right)\left(y\left(a^{*}, z\right)-b-\mu\right)}{r+s+\beta p\left(\theta^{*}\right)}
$$


At the equilibrium, each worker is paid according to his ability level. The wage difference $\left(w(z)^{*}-w\left(\hat{z}^{*}\right)\right)$ is an increasing function of the worker's productivity. Thus, all else being equal, the greater the worker's ability, the greater the wage difference. Firms $i$ who are matched randomly to higher productivity workers (high $z$ ), get higher profits according to (21), (24) and (37), but cannot do anything about it because they are identical.

\section{Comparative Statics}

In this section, we study the effects of unemployment benefits on variables of the model, particulary job complexity. We start by an analytical study of these effects, then turn to quantitative analysis in order to confirm the analytical results and remove any uncertainty.

\subsection{Analytical Study}

We have shown that the marginal productivity is determined by unemployment benefits (equation (30)). By differentiating this condition, we obtain:

$$
d a\left(A^{\prime}(a)+\hat{z}\right)+a d \hat{z}=d b
$$

Combining equations (26) and (38), we deduce the derivative of job complexity, $a$, with respect to unemployment benefits $b$ :

$$
\frac{d a}{d b}=\frac{g(\hat{z})\left(A^{\prime}(a)+\hat{z}\right)}{a A^{\prime \prime}(a)(1-G(\hat{z}))+g(\hat{z})\left(A^{\prime}(a)+\hat{z}\right)^{2}}
$$

Taking into account expression (25), we can verify that the equation (39) numerator is strictly negative. Using the second order conditions (equation (32)), we show that the denominator is also negative. Consequently, the derivative of job complexity $a$ with respect to unemployment benefits $b$ is strictly positive:

$$
\frac{d a}{d b}>0
$$

Using this expression, in conformity with Proposition 1, we establish that the derivative of ability threshold $\hat{z}$ with respect to unemployment benefits $b$ is strictly positive:

$$
\frac{d \hat{z}}{d b}>0
$$


In addition, we show that the derivative of the average productivity (equation (13)) $\bar{y}$ with respect to unemployment benefits $b$ is given by:

$$
\frac{d \bar{y}}{d b}=\left[1+(\bar{z}-\hat{z}) \frac{d a}{d b}\right] \frac{g(\hat{z})(\bar{z}-\hat{z})}{1-G(\hat{z})}>0
$$

In this equation, expression $((\bar{z}-\hat{z}) d a / d b)$, which is strictly positive, measures the unemployment benefits' impact on productivity by increasing job complexity. As a result, we establish the following proposition:

Proposition 2 At the optimum level of profits, an improvement in unemployment benefits makes agents more selective, thus giving firms incentives to create more complex jobs and increasing labour productivity.

In this economy, a public policy such as an unemployment benefit system directly affects firms' technological choices. An increase in benefits, which reinforces workers' bargaining strength, leads to a rise in bargained wages. Firms respond to this situation by requiring a higher ability threshold and creating more complex jobs that are better suited to skilled workers, who become easier to meet. Nevertheless, despite this improvement in matching quality, labour market participation falls as the proportion of workers who are considered unemployable rises. Conversely, the impact on the unemployment rate is ambiguous.

This result shows that the positive impact of unemployment benefits on productivity is reinforced when job complexity is endogenous. On the other hand, the introduction of benefits forces labour market institutions into a tradeoff between participation and productivity.

Other papers (Acemoglu and Shimer 1999; Diamond 1981; Ljungqvist and Sargent 1995) show that unemployment benefits, in enabling workers to choose their job better, improve job quality and global productivity. Along similar lines, Marimon and Zilibotti (1999) show that in a matching model with horizontal differentiation of agents, an increase in unemployment benefits leads to better adjustment of skills to firms' qualification needs. On the contrary, in our model, the unemployment benefits effect on productivity is not only due to selectivity but also to endogenous technological choices. Table 1 summarizes the analytical effects of unemployment benefits:

\begin{tabular}{|c|c|c|c|c|c|c|c|c|c|c|}
\hline & $\theta$ & $\hat{z}$ & $a$ & $\bar{y}$ & $\bar{w}$ & $p(\theta)$ & $q(\theta)$ & $u$ & $\tau=1-G(\hat{z})$ & $\tau(1-u)$ \\
\hline$b$ & $?$ & + & + & + & $?$ & $?$ & $?$ & $?$ & - & $?$ \\
\hline
\end{tabular}

Table 1: Analytical Effects of Unemployment Benefits 
In addition, we note that since increasing the degree of complexity implies a rise in skilled workers' productivity on one hand, and a decrease in unskilled workers' productivity on the other hand, the impact of a variation in unemployment benefits on wages differs according to the wage level considered. Thus, at this stage, although an increase in unemployment benefits implies a rise in the minimum wage, we cannot reach a decisive conclusion about the effect on wage distribution as a whole.

\subsection{Numerical Analysis}

The results of the analytical study indicate that unemployment benefits have ambiguous effects on job creation. In this section, we seek to eliminate ambiguity concerning these effects, and to evaluate their impact on the unemployment rate. We note that this model is calibrated in order to represent a situation similar to the French economy.

In accordance with current real rate, the annual rate of time preference is estimated at 5\%. The job destruction rate is fixed at 0.15 in order to represent an employment flow compatible with the French situation.

We use a Cobb-Douglas function taking the form $\pi(\theta)=h \theta^{\eta}$ to represent the matching function. In accordance with standard matching models (Cahuc and Lehmann 2000; Mortensen and Pissarides 1999), we set the elasticity of this function with respect to vacant job equal, noted $\eta$, at 0.5 . The bargaining power is fixed at 0.5. The Hosios condition is thus satisfied. Unemployment benefits, which are funded by a neutral tax, represent $50 \%$ of wages, while productivity of household production is fixed at $5 \%$. In this economy, for an unemployment benefit level of 0.5 , the unemployment rate reaches $11.46 \%$. Parameter values are summarized in Table 2.

\begin{tabular}{|c|c|c|c|c|c|c|c|}
\hline$r$ & $s$ & $\beta$ & $\eta$ & $h$ & $c$ & $b$ & $\mu$ \\
\hline 0.05 & 0.15 & 0.5 & 0.5 & 1.1 & 0.35 & 0.5 & 0.05 \\
\hline
\end{tabular}

Table 2: The Model Calibration

For these simulations, we assume that the complexity function $A(a)$ is quadratic $\left(A(a)=-a^{2}\right)$. Qualification level is distributed among workers according to a continuous distribution, $G(z)$, with $G(z)=\alpha\left(z-z_{\min }\right)$.

Figure 2 illustrates the unemployment benefits' effects on variables of the model. As shown in the comparative statics section, a rise in unemployment benefits affects agents' selectivity by leading to a higher required ability threshold, and hence a higher level of $\hat{z}$. As a result of this selectivity, firms adapt their technological choices to skilled workers by creating more complex jobs. In 
spite of the productivity improvement, the labour market tightness falls. This negative impact on job creation can be explained as follows. Given that unemployment benefits improve the lifetime utility of the unemployed, the firms' share of the global surplus is reduced as the workers' bargaining strength is reinforced. As a consequence, firms have less incentive to create jobs despite the increase in labour productivity. The probability $p(\theta)$ that employable workers will find a job decreases and the unemployment rate increases. Nevertheless, firms will have less difficulty in filling their job vacancy, as $q(\theta)$ rises. The results of our simulations are summarized in the following table :

\begin{tabular}{|c|c|c|c|c|c|c|c|c|c|c|}
\hline & $\theta$ & $\hat{z}$ & $a$ & $\bar{y}$ & $\bar{w}$ & $p(\theta)$ & $q(\theta)$ & $u$ & $\tau=1-G(\hat{z})$ & $\tau(1-u)$ \\
\hline$b$ & - & + & + & + & + & - & + & + & - & - \\
\hline
\end{tabular}

Table 3: Numerical Analysis

At this stage, considering the effect on the minimum wage and the average wage, we can add that an increase in unemployment benefits is generally to the advantage of workers.

\section{Final comments}

In most of the literature, job complexity is seen as an exogenous variable. We have shown here that it can be considered a rational corporate response. When the agents become more selective by fixing a higher ability threshold, job complexity is reinforced. In this context, firms adjust the two variables of selectivity and complexity in maximization of the value of their vacant job.

We then analyzed unemployment benefit effects on technological choices. We have shown that an improvement in the unemployment benefit system increases selectivity and job complexity at the expense of lesser-qualified workers, thus reducing the labour market participation rate. These two effects lead to an improvement in matching quality which increases productivity in this economy.

Although matching becomes more productive and efficient, when technological choices are endogenous, a rise in unemployment benefits appears to have a negative impact on job creation. In short, the introduction of unemployment benefit forces labour market institutions into a trade-off between productivity and participation. 


\section{References}

[1] Acemoglu D (1998) Why do new technologies complement skills ? directed technical change and wage inequality. Quarterly Journal of Economics 113(4):1055-1090.

[2] Acemoglu D (2002) Technical change, inequality and the labour market. Journal of Economic Literature 40(1):7-73.

[3] Acemoglu D (2003) Patterns of skill premia. Review of Economic Studies 70(2):199-230.

[4] Acemoglu D, Shimer R (1999) Efficient unemployment insurance. Journal of Political Economy 107(5):893-928.

[5] Agell J (1999) On the benefits from rigid labour markets: Norms, market failures, and social insurance. Economic Journal 109(453):143-164.

[6] Aghion P, Howitt P (2002) Wage inequality and the new economy. Oxford Review of Economic Policy 18(3):306-323.

[7] Autor DH, Katz LF, Krueger AB (1998) Computing inequality : have computers changed the labour market ?. Quarterly Journal of Economics 113(4):1169-1214.

[8] Barrell R, Lansbury M, Morgan J, Pain N (1995) US labour markets, the process of job creation. National Institute Economic Review 406:1-20.

[9] Berman E, Bound J, Griliches Z (1994) Changes in the demand for skilled labour within U.S. manufacturing industries: evidence from the annual survey of manufactures. Quarterly Journal of Economics 109(2):367-397.

[10] Boone J, Van Ours JC (2000) Modeling financial incentives to get unemployed back to work. ftp://repec.iza.org/RePEc/Discussionpaper/dp108.pdf.

[11] Boone J, Van Ours JC (2004) Effective active labour market policies. $\mathrm{ftp}$ ://repec.iza.org/RePEc/Discussionpaper/dp1335.pdf.

[12] Bound J, Johnson G (1992) Changes in the structure of wages in the 1980s : an evaluation of alternative explanations. American Economic Review 82(3):371-392.

[13] Cahuc P, Lehmann E (2000) Should unemployment benefits decrease with unemployment spell ?. Journal of Public Economics 77 (1):135-153.

[14] Diamond PA (1981) Mobility costs, frictional unemployment, and efficiency. Journal of Political Economy 89(4):798-812.

[15] Fredriksson P, Holmlund B (2001) Optimal unemployment insurance in search equilibrium. Journal of labour Economics 19(2):370-400. 

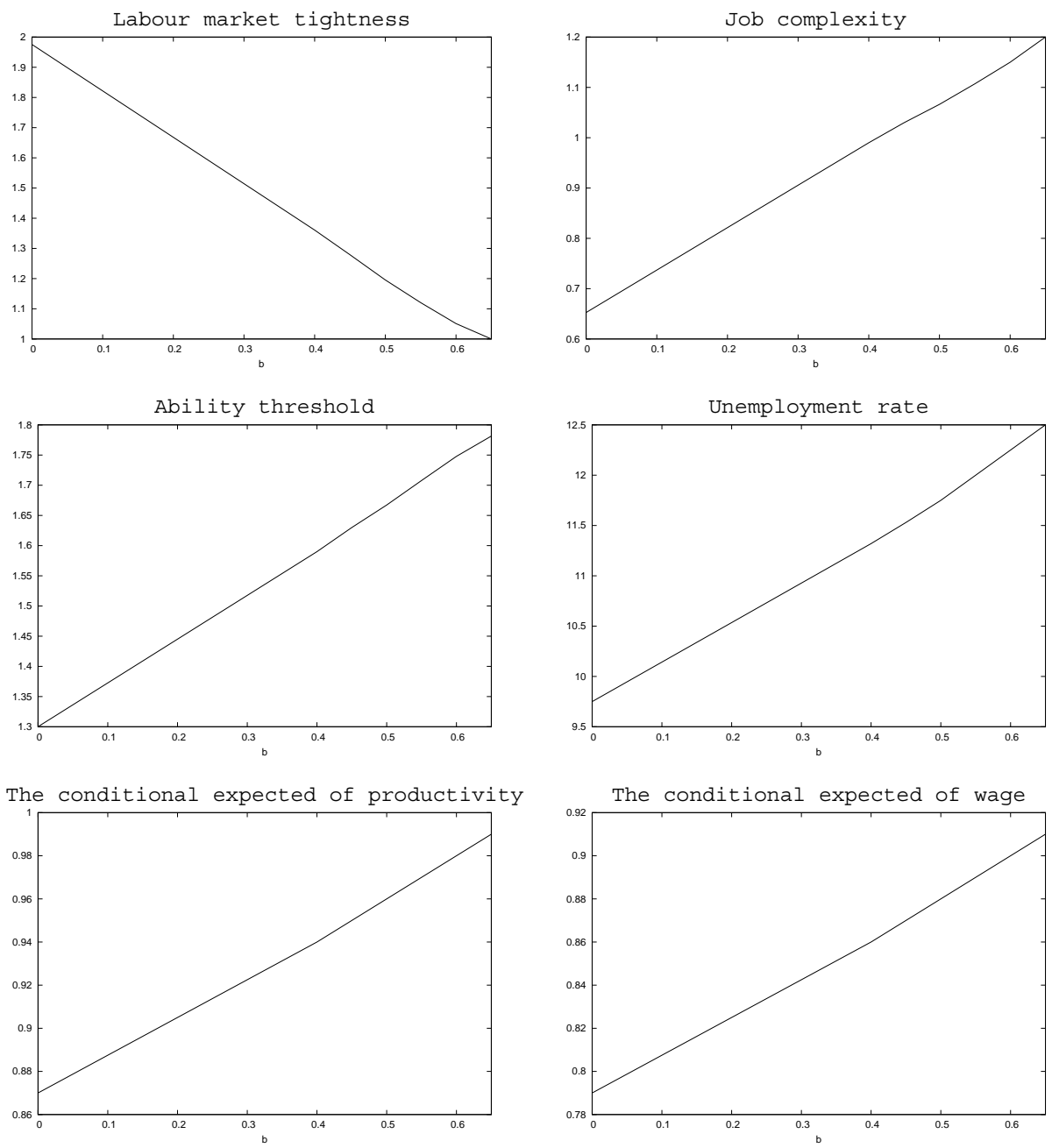

Figure 2: Impact of Unemployment Benefits on Model Variables 
[16] Funk P, Vogel T (2004) Endogenous skill bias. Journal of Economic Dynamics and Control 28(1):2155-2193.

[17] Galor O, Maov O (2000) Ability biased technological transition, wage inequality and economic growth. Quarterly Journal of Economics 115(2):469497.

[18] Hopenhayn HA, Nicolini JP (1997) Optimal unemployment insurance. Journal of Political Economy 105(2):412-438.

[19] Ljungqvist L, Sargent T (1995) The swedish unemployment experience. European Economic Review 39(5):1043-1070.

[20] Machin S, Manning A (1999) The causes and consequences of longterm unemployment in Europe. In: Ashenfelter O, Card D (eds) Handbook of Labour Economics. North-Holland, Amsterdam, pp 3085-3139.

[21] Machin S, Van Reenen J (1998) Technology and changes in skill structure : evidence from seven OECD countries. Quarterly Journal of Economics 113(4):1215-1244.

[22] Manacorda M, Petrongolo B (1999) Skill mismatch and unemployment in OECD countries. Economica 66(262):181-207.

[23] Pissarides CA (2000) Equilibrium unemployment theory. MIT Press, Cambridge.

[24] Saint-Paul G (1995) The high unemployment trap. Quarterly Journal of Economics 110(2):527-550.

[25] Shavell S, Weiss L (1979) The optimal payment of unemployment insurance benefits over time. Journal of Political Economy 87(6):1347-1362.

[26] Siebert H (1997) Labour market rigidities : at the root of unemployment in Europe. Journal of Economic Perspectives 11(3):37-54.

[27] Strand J (2002) Wage bargaining and turnover costs with heterogeneous labour and perfect history screening. European Economic Review 46(7):1209-1227. 


\section{Appendix}

\section{The value of vacant job- $i$}

The objective of this appendix is to deduce an expression $J_{v i}$ of vacant job depending on the choice variables of firm- $i$. The equations (8) and (10) can be written as follows:

$$
\begin{gathered}
(r+s)\left(W_{i}(z)-W_{u}(z)\right)=w_{i}(z)-r W_{u}(z) \\
(r+s)\left(J_{i}(z)-J_{v i}\right)=y_{i}\left(a_{i}, z\right)-w_{i}(z)-r J_{v i}
\end{gathered}
$$

Using these latter equations, we establish:

$$
(r+s) S_{i}(z)=y_{i}\left(a_{i}, z\right)-r\left(J_{v i}+W_{u}(z)\right)
$$

Taking account of the sharing surplus rule (equation (17)), we obtain:

$$
J_{i}(z)-J_{v i}=(1-\beta) \frac{y_{i}\left(a_{i}, z\right)-r\left(J_{v i}+W_{u}(z)\right)}{r+s}
$$

Substituting this latter expression in equation (12), we deduce the expression (20) of vacant job $J_{v i}$.

\section{The first order condition}

At the symmetric state, condition (29) implies:

$$
y(a, \hat{z})-r\left(W_{u}(\hat{z})+J_{v}(\hat{z})\right)=0
$$

According to this latter equation and to the sharing surplus rule, we obtain that ability threshold $\hat{z}$ cancels the global surplus:

$$
S(\hat{z})=0
$$

As a consequence, the lifetime utilities and the value of vacant or filled jobs satisfy:

$$
\begin{gathered}
W(\hat{z})=W_{u}(\hat{z}) \\
J(\hat{z})=J_{v}(\hat{z})
\end{gathered}
$$

Using equations (26) and (27), we obtain the equilibrium expression (30). 


\section{The second order conditions}

In this appendix, we show that second order conditions satisfy expression (32). Using equation (20), we establish the following second derivatives:

$$
\begin{gathered}
r \frac{\partial^{2} J_{v i}}{\partial a_{i}^{2}}=\frac{q(\theta)(1-\beta)}{(1-G(\hat{z}))(r+s)}\left[\left(1-G\left(\hat{z}_{i}\right)\right)\left(A^{\prime \prime}\left(a_{i}\right)-r \frac{\partial^{2} J_{v i}}{\partial a_{i}^{2}}\right)\right] \\
r \frac{\partial^{2} J_{v i}}{\partial \hat{z}_{i}^{2}}=\frac{q(\theta)(1-\beta)}{(1-G(\hat{z}))(r+s)}\left[-g\left(\hat{z}_{i}\right)\left(a_{i}-r \frac{\partial W_{u}\left(\hat{z}_{i}\right)}{\partial \hat{z}_{i}}\right)-r\left(1-G\left(\hat{z}_{i}\right)\right) \frac{\partial^{2} J_{v i}}{\partial \hat{z}_{i}^{2}}{ }_{(52)}\right. \\
r \frac{\partial^{2} J_{v i}}{\partial a_{i} \partial \hat{z}_{i}}=\frac{q(\theta)(1-\beta)}{(1-G(\hat{z}))(r+s)}\left[\left(1-G\left(\hat{z}_{i}\right)\right)\left(\frac{\partial \bar{z}_{i}}{\partial \hat{z}_{i}}-r \frac{\partial^{2} J_{v i}}{\partial a_{i} \partial \hat{z}_{i}}\right)\right]
\end{gathered}
$$

Let's note :

$$
\alpha=\frac{q(\theta)(1-\beta)}{r(r+s)}\left[1+\frac{q(\theta)(1-\beta)}{(r+s)}\right]^{-1}=\frac{q(\theta)(1-\beta)}{r(r+s+q(\theta)(1-\beta))}>0
$$

We have then:

$$
\begin{gathered}
\frac{\partial^{2} J_{v i}}{\partial a_{i} \partial \hat{z}_{i}}=\alpha \frac{\partial \bar{z}_{i}}{\partial \hat{z}_{i}}=\frac{-\alpha g\left(\hat{z}_{i}\right)}{1-G\left(\hat{z}_{i}\right)}\left(A^{\prime}\left(a_{i}\right)+\hat{z}_{i}\right)>0 \\
\frac{\partial^{2} J_{v i}}{\partial a_{i}^{2}}=\alpha A^{\prime \prime}\left(a_{i}\right)<0 \\
\frac{\partial^{2} J_{v i}}{\partial \hat{z}_{i}^{2}}=\frac{\alpha g\left(\hat{z}_{i}\right)}{1-G(\hat{z})}\left[-a_{i}+r \frac{\partial W_{U}\left(\hat{z}_{i}\right)}{\partial \hat{z}_{i}}\right]
\end{gathered}
$$

In order to determinate the sign of $\partial^{2} J_{v i} / \partial \hat{z}_{i}^{2}$, we have to calculate $\partial W_{u}\left(\hat{z}_{i}\right) / \partial \hat{z}_{i}$. Using equations (22) and (23) :

$$
W_{i}\left(\hat{z}_{i}\right)-W_{u}\left(\hat{z}_{i}\right)=\frac{\beta}{1-\beta} \frac{y_{i}\left(a_{i}, \hat{z}_{i}\right)-w_{i}\left(\hat{z}_{i}\right)}{r+s}
$$




$$
W_{i}\left(\hat{z}_{i}\right)-W_{u}\left(\hat{z}_{i}\right)=\frac{w_{i}\left(\hat{z}_{i}\right)-b-\mu}{r+s+p(\theta)}
$$

We deduce then :

$$
\begin{gathered}
\frac{\partial\left(W_{i}\left(\hat{z}_{i}\right)-W_{u}\left(\hat{z}_{i}\right)\right)}{\partial \hat{z}_{i}}=\frac{\beta}{(1-\beta)(r+s)} \frac{\partial\left(y_{i}\left(\hat{z}_{i}\right)-w_{i}\left(\hat{z}_{i}\right)\right)}{\partial \hat{z}_{i}} \\
\frac{\partial\left(W_{i}\left(\hat{z}_{i}\right)-W_{u}\left(\hat{z}_{i}\right)\right)}{\partial \hat{z}_{i}}=\frac{1}{r+s+p(\theta)} \frac{\partial w_{i}\left(\hat{z}_{i}\right)}{\partial \hat{z}_{i}}
\end{gathered}
$$

Combining these two latter equations (60) and (61), we obtain:

$$
\frac{1}{r+s} \frac{\partial\left(y_{i}\left(\hat{z}_{i}\right)-w_{i}\left(\hat{z}_{i}\right)\right)}{\partial \hat{z}_{i}}=\frac{a_{i}(1-\beta)}{\beta p(\theta)+r+s}
$$

Taking account the lifetime utility of workers and unemployed, this expression (62) can be written as follows:

$$
r \frac{\partial W_{u}\left(\hat{z}_{i}\right)}{\partial \hat{z}_{i}}=\frac{a_{i} \beta p(\theta)}{(r+s+\beta p(\theta))}
$$

We deduce:

$$
r \frac{\partial W_{u}\left(\hat{z}_{i}\right)}{\partial \hat{z}_{i}}=\frac{a_{i} \beta p(\theta)}{(r+s+\beta p(\theta))}<a_{i}
$$

We obtain then:

$$
\frac{\partial^{2} J_{v i}}{\partial \hat{z}_{i}^{2}}=\frac{\alpha g\left(\hat{z}_{i}\right)}{1-G(\hat{z})}\left[-a_{i}+r \frac{\partial W_{u}\left(\hat{z}_{i}\right)}{\partial \hat{z}_{i}}\right]<0
$$

Furthermore, the maximisation of $J_{v i}$ with respect to $\left(\hat{z}_{i}, a_{i}\right)$ satisfies :

$$
\frac{\partial^{2} J_{v i}}{\partial a_{i}} \frac{\partial^{2} J_{v i}}{\partial \hat{z}_{i}^{2}}-\left(\frac{\partial^{2} J_{v i}}{\partial a_{i}^{2} \partial \hat{z}_{i}}\right)^{2} \geq 0
$$

At the symmetric equilibrium, this condition is equivalent to:

$$
-\frac{A^{\prime \prime}(a) g(\hat{z})}{1-G(\hat{z})}\left[a-\frac{a \beta p(\theta)}{(r+s+\beta p(\theta))}\right]-\left[\frac{g(\hat{z})}{1-G(\hat{z})}\right]^{2}\left(A^{\prime}(a)+\hat{z}\right)^{2} \geq 0
$$

